\title{
Pleural Effusion in Multiple Myeloma
}

\author{
Zhuo Wang ${ }^{1}$, Guoguang $\mathrm{Xia}^{1}$, Ling $\mathrm{Lan}^{2}$, Fayong Liu ${ }^{1}$, Yanxun Wang ${ }^{1}$, Baoyue Liu ${ }^{3}$, \\ Yi Ding ${ }^{3}$, Li Dai ${ }^{1}$ and Yunjian Zhang ${ }^{1}$
}

\begin{abstract}
Objective Pleural effusion is rarely observed in patients with multiple myeloma (MM). Myeloma cell infiltration or invasion to the pleura is very rare. This study aimed to investigate the clinical characteristics of pleural effusion in patients with MM.

Methods We retrospectively reviewed the medical records of patients diagnosed with pleural effusion, MM, and pleural effusion with MM between 2004 and 2014 at Beijing Jishuitan Hospital. The present study included patients with pleural effusion who underwent cytological, bacteriological, biochemical and other testing. The cytopathology of abnormal pleural effusion cells was not diagnostic, thus flow cytometry was performed. MM was defined using the diagnosis standard of NCCN Clinical Practice Guidelines in Oncology (NCCN Guidelines) 2014 for MM.

Results This study included 3,480 pleural effusion patients and 319 MM patients. There were 34 patients with both MM and pleural effusion (17 men and 17 women). The average age was 63 years (range, 48-84 years). Pleural effusion with MM was caused by congestive heart disease, chronic renal failure, hypoalbuminemia, pulmonary infarctions, cirrhosis, pulmonary arterial hypertension, parapneumonic effusion, tuberculous pleural effusion, and myelomatous pleural effusion (MPE). The diagnosis of MPE was confirmed by the detection of myeloma cells in the pleural fluid using flow cytometric analyses. There were only 2 MPE cases in our study. The first MPE case was a woman. The first clinical manifestation was pleural effusion, and the diagnosis was non-secretory MM, DSS stage IIIA (Durie-Salmon staging system); ISS stage I (the International Staging System). The second MPE case was a man who was diagnosed with MM IgA- $\kappa$, DSS stage IIIA; ISS stage II.

Conclusion The detection rate of MPE was very low. MPE tended to present with yellow exudates and the lack of physical and chemical characteristics. Furthermore, patients with MPE exhibited many yellow nodules on the pleura. These nodules were lobulated and had abundant blood supply. The routine pleural effusion pathological examination had low sensitivity. Flow cytometry may be more useful for improving the detection rate of MPE.
\end{abstract}

Key words: pleural effusion, multiple myeloma, flow cytometry

(Intern Med 55: 339-345, 2016)

(DOI: 10.2169/internalmedicine.55.4733)

\section{Introduction}

Pleural effusion is rarely observed in patients with multiple myeloma (MM). Approximately $6 \%$ of patients with MM develop pleural effusion. Pleural effusions in MM are generally benign and due to congestive heart disease, chronic renal failure, hypoalbuminemia, cardiac amyloidosis, pulmonary infarctions, or infections (1-11). Myelomatous pleural effusion (MPE) results in less than $1 \%$ of all cases (1). We herein describe 34 cases of MM with pleural effusion treated at our hospital over the past decade. Our study investigated patients that present with pleural effusion as the first clinical manifestation of MM and those with pleural effusion that occurred during the course of treatment of MM.

\footnotetext{
${ }^{1}$ Department of Respiratory Medicine, Beijing Jishuitan Hospital, China, ${ }^{2}$ Department of Endocrinology, Beijing Jishuitan Hospital, China and ${ }^{3}$ Department of Pathology, Beijing Jishuitan Hospital, China

Received for publication December 25, 2014; Accepted for publication May 31, 2015

Correspondence to Dr. Zhuo Wang, grace_wang358@hotmail.com
} 
Table. Causes of Pleural Effusion in the 34 Patients.

\begin{tabular}{lr}
\hline Cause & Number of cases \\
\hline Parapneumonic effusion & 17 \\
Tuberculous pleuritis & 1 \\
Congestive heart disease & 3 \\
Chronic renal failure & 6 \\
Hypoalbuminemia & 4 \\
Cirrhosis & 1 \\
Pulmonary arterial hypertension & 1 \\
Pulmonary infarctions & 1 \\
Myelomatous pleural effusion & 2 \\
Multi-factor\# & 8 \\
\hline \#Two or more causes. &
\end{tabular}

\section{Materials and Methods}

We retrospectively reviewed the medical records of patients diagnosed with pleural effusion, MM, and pleural effusion with MM between 2004 and 2014 at Beijing Jishui$\tan$ Hospital. The diagnostic criterion of pleural effusion was finding effusion by thoracentesis after imaging examinations (chest X-ray, chest CT or ultrasound).

Pleural effusion examinations included a description of the color and characteristics, cellular classification and cell counts, qualitative and quantitative detection of the levels of protein, glucose, chloride, lactate dehydrogenase, adenosine deaminase, carcinoembryonic antigen, alpha-fetoprotein, CA125, and CA19-9, acid-fast staining, bacterial cultures (aerobic and anaerobic), and pleural effusion pathology examinations. The cytopathology of abnormal pleural effusion cells was not diagnostic, thus flow cytometric analyses were performed.

Flow cytometric (FACSCalibur, BD Biosciences, Franklin Lakes, USA) analyses of pleural effusion were performed for select cases. Using flow cytometry, normal and abnormal cells were identified by fluorescein-labeled monoclonal antibodies, cell antigens, cell size, and the number of particles within the cells. Monoclonal antibodies and reagents were purchased from BD Biosciences. Data were analyzed using the Cell Quest Pro software program (BD Biosciences). MM was defined according to the diagnosis standard of NCCN Clinical Practice Guidelines in Oncology (NCCN Guidelines) 2014 for MM.

\section{Results}

We collected data from 3,480 patients who were diagnosed with pleural effusion and 319 patients who were diagnosed with MM from February 2004 to February 2014 at Beijing Jishuitan Hospital, China. Thirty-four patients had both MM and pleural effusion (17 men and 17 women). The average age of the 34 patients was 63 years (range, 48-84 years). In these patients, a routine cytopathological examination of the pleural effusion smear was performed. One patient had a pleural biopsy histopathology examination, and the samples from two patients were analyzed using flow cytometry to evaluate pleural effusion.

The causes of pleural effusion in the 34 patients are described in Table. Two MM patients with myeloma infiltration to the pleural cavity included one patient with pleural effusion as the first manifestation when she was treated in the respiratory department. The characteristics of pleural effusion in the 34 patients were as follows: 21 exudates, 13 transudates, 27 were unilateral, and seven were bilateral. The amount of effusion was medium or small when pleural effusion was found.

\section{Details of the two cases of MPE}

A 69-year-old woman was admitted to the respiratory ward in Beijing Jishuitan Hospital in the beginning of April, 2013 after experiencing chest pain and a fever. More than 10 days before admission, the patient felt chest tightness without obvious inducement and had shortness of breath and position-related left chest pain. She also had weakness in the lower extremities and difficulty in sitting up; her chest pain was relieved after activity. One week prior to admission she experienced a fever, which began in the afternoon without an obvious cause and persisted until admission. The highest temperature was $37.7^{\circ} \mathrm{C}$, accompanied by chills. The fever was relieved without treatment. She had no cough or sputum. Six days before admission, she came to the outpatient department. Chest CT was performed, and bilateral pleural effusion was found with a medium amount of pleural effusion in the right chest and a small amount in the left chest. There were nodules under the pleura. Atelectasis and streaks shadow were observed at the middle lobe and inferior lobe of the right lung. There were low-density lesions at the thoracic vertebra, ribs, and sternum. The density of the bone marrow cavity increased and uneven thickening of the soft tissues located in the thoracic vertebrae was observed (Fig. 1-3). During her illness, she felt weak but always had a good appetite and her bowel movements and micturition remained normal. Her body weight did not change considerably. She had a history of hypertension for 7-8 years. Benazepril hydrochloride tablets (Lotensin) and acid levamlodipine (patronizing up) were taken to control her blood pressure. She had a history of diabetes for 7-8 years. Her blood sugar levels were satisfactorily controlled using metformin. She had no history of coronary heart disease, hepatitis, or tuberculosis. Her family history was unremarkable except that her twin sister died of leukemia approximately one year previously.

The patient's body temperature was $36.5^{\circ} \mathrm{C}$, breathing rate was $20 \mathrm{bpm}$, blood pressure was $123 / 73 \mathrm{mmHg}$ and heart beat was $85 \mathrm{bpm}$. She was well developed and moderately nourished. The patient had a clear mental state. No lymph nodes were palpable in the superficial areas of the body. There was no tenderness of the chest wall. Dullness could be heard in both of the lower lungs. There were no abnormalities in the heart or abdomen, or edema in the lower extremities. She had good voluntary movement of the spine 


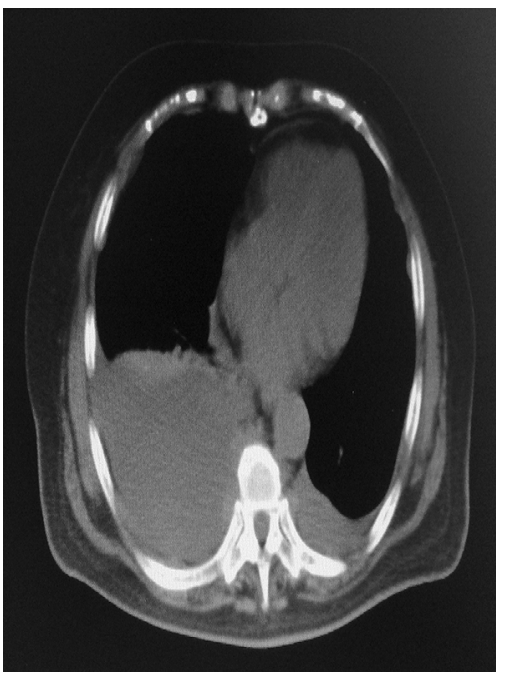

Figure 1. Chest CT. Bilateral pleural effusion was found with a medium amount of pleural effusion in the right chest and a small amount in the left chest. There were nodules under the pleura. There were low-density lesions at the thoracic vertebra, ribs, and the sternum. The density of bone marrow cavity increased. And uneven thickening of soft tissues located in the thoracic vertebrae.

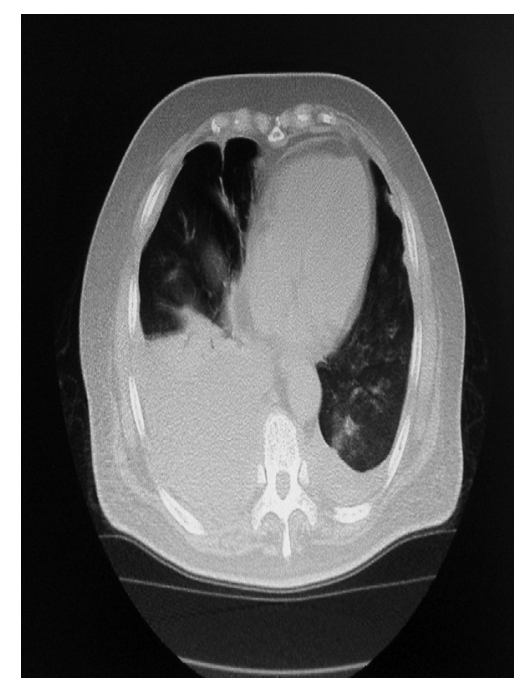

Figure 3. Chest CT. Atelectasis and streaks shadow were seen at the middle lobe and inferior lobe of the right lung.

and extremities and no tenderness.

Laboratory examinations (End of March, 2013) showed blood leukocytes were $4.49 \times 10^{9} / \mathrm{L}$, neutrophil granulocytes were $71.3 \%$, hemoglobin was $103 \mathrm{~g} / \mathrm{L}$, hematocrit was $31.8 \%$, the platelet count was $233 \times 10^{9} / \mathrm{L}$, and the erythrocyte sedimentation rate was $65 \mathrm{~mm} / \mathrm{h}$ (Westergren ESR). The level of alanine aminotransferase was 7 IU/L, aspartate transaminase was $12 \mathrm{IU} / \mathrm{L}$, total protein was $58.6 \mathrm{~g} / \mathrm{L}$, albu$\min$ was $43.6 \mathrm{~g} / \mathrm{L}$, globulin was $15 \mathrm{~g} / \mathrm{L}$, the albumin/globulin ratio was 2.91 , blood glucose was $5.6 \mathrm{mmol} / \mathrm{L}$, blood urea nitrogen was $8.7 \mathrm{mmol} / \mathrm{L}$, blood creatinine was 71 $\mathrm{mmol} / \mathrm{L}$, blood prealbumin was $208 \mathrm{mg} / \mathrm{L}$, and lactate dehydrogenase was 204 IU/L. The serum potassium, sodium, and

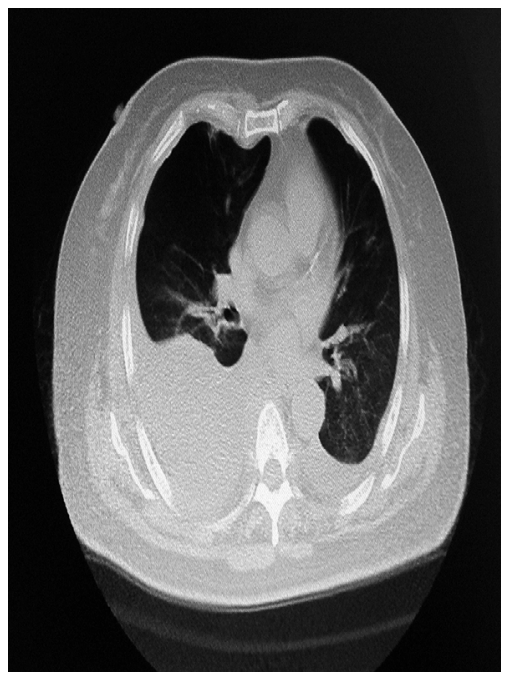

Figure 2. Chest CT. Atelectasis and streaks shadow were observed at the middle lobe and inferior lobe of the right lung.

chloride levels were normal. Extractable nuclear antigens and antinuclear antibodies were negative. Fibrinogen was $407.7 \mathrm{mg} / \mathrm{dL}$ and D-dimer was $1.08 \mathrm{mg} / \mathrm{L}$. The prothrombin time and activated partial thromboplastin time were normal. The blood adenosine deaminase level was $11 \mathrm{U} / \mathrm{L}$. The serum level of carcinoembryonic antigen was $0.74 \mathrm{ng} / \mathrm{mL}, \mathrm{CA}$ 125 was $86.95 \mathrm{U} / \mathrm{mL}$, CA19-9 was $9.62 \mathrm{U} / \mathrm{mL}, \mathrm{CA} 15-3$ was 10.29 U/mL, and alpha-fetoprotein was $2.92 \mathrm{ng} / \mathrm{mL}$. The serum level of squamous cell carcinoma antigen was $0.5 \mathrm{ng} /$ $\mathrm{mL}$, peculiarity alkene alcoholization enzyme was $17.5 \mathrm{ng} /$ $\mathrm{mL}$, and cytokeratin 19 fragment was $1.7 \mathrm{ng} / \mathrm{mL}$. The complete blood $\mathrm{T}$ cells were $76.2 \%$, helper $\mathrm{T}$ cells were $50.5 \%$, cytotoxic $\mathrm{T}$ cells were $17.6 \%$, and the helper $\mathrm{T}$ cell/cytotoxic $\mathrm{T}$ cell ratio was 2.9 . The procalcitonin level was less than $0.01 \mathrm{ng} / \mathrm{mL}$. Rheumatoid factor was less than $20 \mathrm{IU} /$ $\mathrm{mL}$. The level of antistreptolysin $\mathrm{O}$ was less than $25 \mathrm{IU} / \mathrm{mL}$ and C-reaction protein was $6.63 \mathrm{mg} / \mathrm{L}$. Hepatitis B antibodies and antigens were negative, hepatitis $\mathrm{C}$ antibody was negative, and HIV antibody and syphilis antibodies were negative.

In the beginning of April, 2013, the patient's effusion in the right pleura was light yellow in color and showed mild turbidity. The leukocyte count in the pleural effusion was $816 / \mathrm{mm}^{3}$, and the mononuclear cells accounted for $96 \%$ and multinucleated cells accounted for $4 \%$. The pleural effusion protein qualitative test was positive. In the pleural effusion specimen, the level of glucose was $79 \mathrm{mg} / \mathrm{dL}$, protein was $3,300 \mathrm{mg} / \mathrm{dL}$, chloride was $649 \mathrm{mg} / \mathrm{dL}$, lactate dehydrogenase was $200 \mathrm{IU} / \mathrm{L}$, adenosine deaminase was $10 \mathrm{U} / \mathrm{L}$, carcinoembryonic antigen was $0.55 \mathrm{ng} / \mathrm{mL}$, alpha-fetoprotein was $1.56 \mathrm{ng} / \mathrm{mL}, \mathrm{CA} 125$ was $997.8 \mathrm{U} / \mathrm{mL}, \mathrm{CA} 19-9$ was $0.92 \mathrm{U} /$ $\mathrm{mL}$, and CA15-3 was $5.74 \mathrm{U} / \mathrm{mL}$. Acid fast staining of the pleural effusion was negative. Additionally, a bacterial culture of the pleural effusion was negative.

In the beginning of May, 2013, the patient's urinary $\kappa$ light chain level was less than $1.85 \mathrm{mg} / \mathrm{dL}$ (negative) and the urinary $\lambda$ light chain level was less than $5.00 \mathrm{mg} / \mathrm{dL}$ 


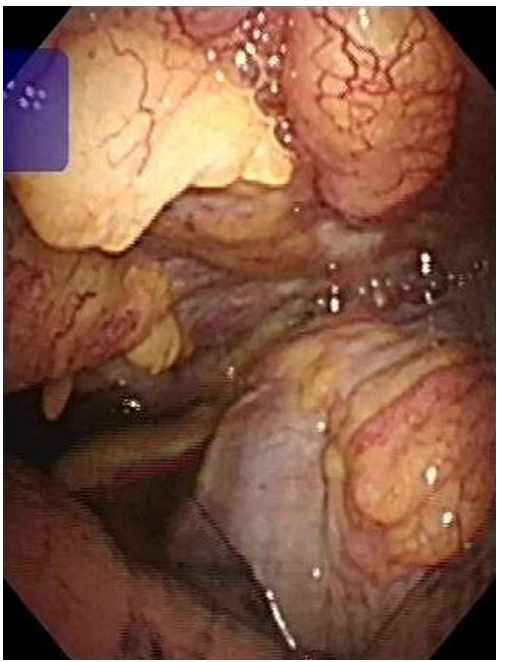

Figure 4. See under thoracoscope. Biopsy was performed at the nodules. Multiple yellow nodules on the parietal pleura can be seen.

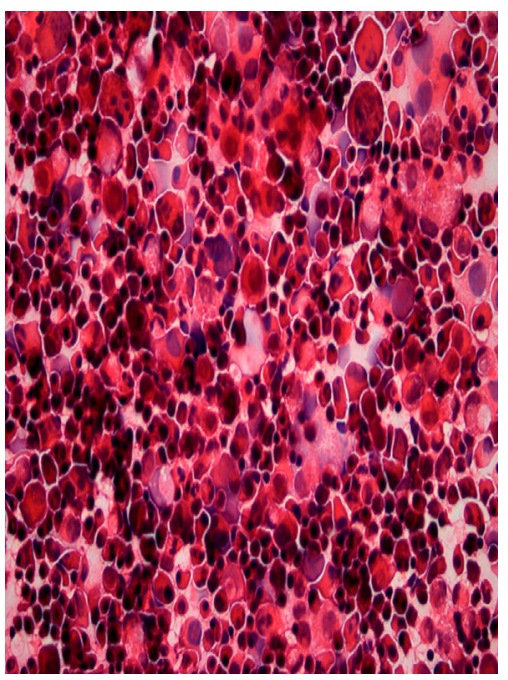

Figure 6. Pleural effusion cell smear. Bulky, nuclear cytoplasm ratio increased malignant cells. H\&E staining, $\times 40$.

(negative). The urinary albumin level was normal. Serum immunofixation electrophoresis did not show the presence of $\mathrm{IgG}, \operatorname{Ig} \mathrm{A}, \operatorname{IgM}, \kappa$ light chain or $\lambda$ light chain monoclonal proteins. The serum level of $\operatorname{IgG}$ was $3.26 \mathrm{~g} / \mathrm{L}, \operatorname{IgA}$ was $0.08 \mathrm{~g} / \mathrm{L}, \mathrm{IgM}$ was $0.06 \mathrm{~g} / \mathrm{L}, \mathrm{C} 3$ was $0.97 \mathrm{~g} / \mathrm{L}$, and $\mathrm{C} 4$ was $0.23 \mathrm{~g} / \mathrm{L}$. The serum level of $\kappa$ light chain was $2.62 \mathrm{~g} / \mathrm{L}, \lambda$ light chain was $1.88 \mathrm{~g} / \mathrm{L}$, and the $\kappa / \lambda$ ratio was 1.39 . The serum level of parathyroid hormone was $59.9 \mathrm{pg} / \mathrm{mL}$.

End of March, 2013, using local anesthesia, thoracoscopy was performed on the right side of the patient's chest. The endoscopic findings (Fig. 4) showed multiple yellow nodules on the pleura. These nodules were lobulated and had abundant blood supply.

A biopsy was performed at the nodules, and the pleural effusion was aspirated. After centrifugation of the pleural effusion, the cells were smeared (Fig. 5, 6) and malignant cells were observed at a large volume and increased nuclear

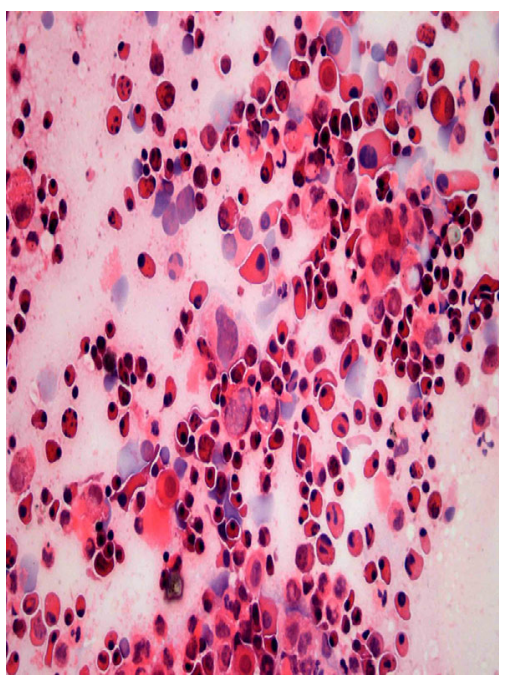

Figure 5. Pleural effusion cell smear. Bulky, nuclear cytoplasm ratio increased malignant cells. Hematoxylin and Eosin (H\&E) staining $\times \mathbf{4 0}$.

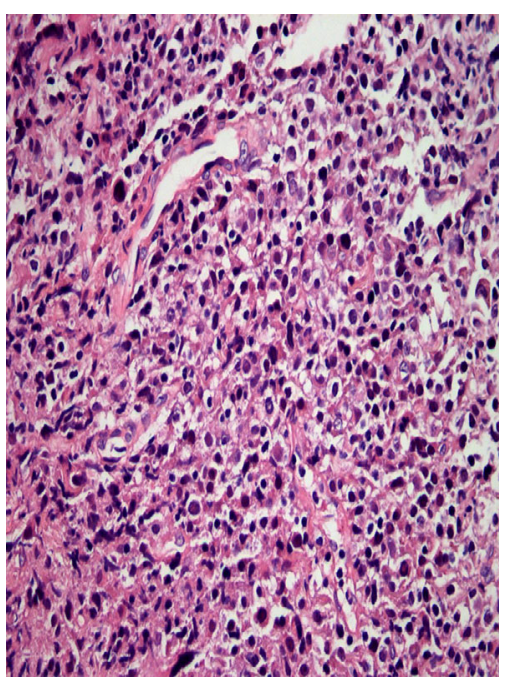

Figure 7. Pleural biopsy pathology slice. Cell were squeezed. The nuclear/cytoplasm ratio was extremely high. The cytoplasm has almost disappeared, and different sizes of nuclei are strongly stained. These characteristics conformed to characteristics of malignant cells. $\mathrm{H} \& \mathrm{E}$ staining, $\times \mathbf{4 0}$.

cytoplasm ratio. A histopathological examination of the biopsy specimen (Fig. 7) showed crowded cells, and the nuclear/cytoplasm ratio was particularly high. The cytoplasm of the cells had nearly disappeared, and different-sized nuclei were strongly stained (Hematoxylin and Eosin H\&E staining). Those characteristics were consistent with the characteristics of malignant cells. Immunohistochemical staining was positive for CD3 (scattered cells), CD31 (positive for vessels), CD43 (a small amount of positive staining), $\mathrm{CK}$ (spotty positive staining), Ki-67 (15\% positive), LCA (scattered cells), CD38 (weakly positive), MC (spotty positive staining), D2-40 (spotty positive staining), CD138, MUM1, and vimentin (weakly positive). Immunohistochemical staining was negative for CD20, CD56, CD99, CK20, 

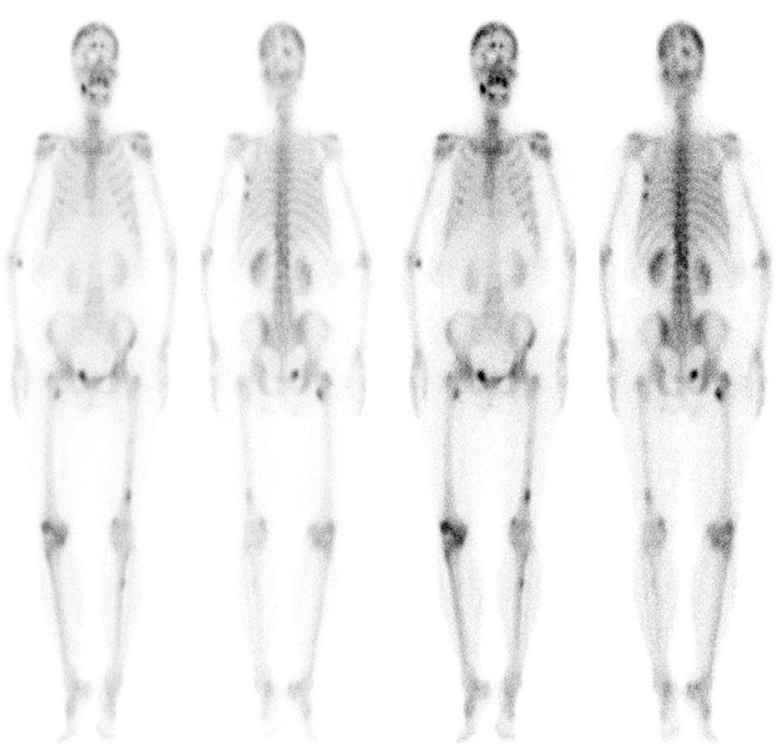

Figure 8. A bone scan. A bone scan (in the beginning of April, 2013) showed uneven distribution of elevated radioactivity at the skull and increased punctate distribution of radioactivity at left rib numbers 5 and 6 . The scan also showed uneven distribution of increased radioactivity at T11-L1 vertebrae, including sparse areas with radioactivity, and increased radioactivity at right tuberositas femoris, left femur, and left tibia.

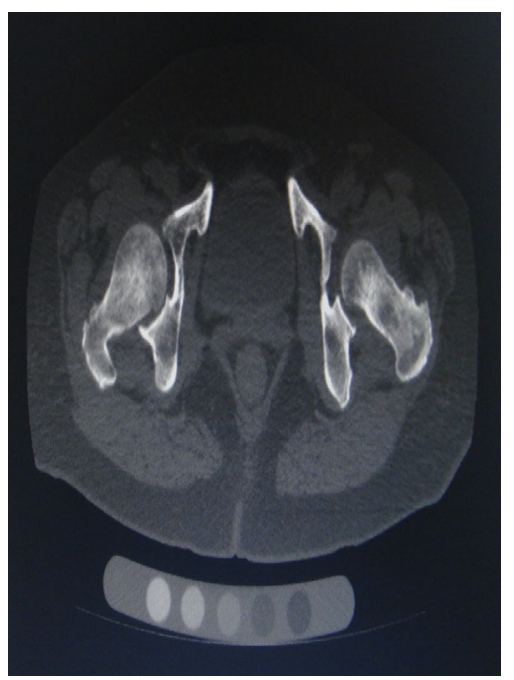

Figure 10. Pelvic CT show small, patchy, low-density shadows at bilateral femurs.

CgA, EMA, S-100, SY, TTF-1, CD79a, calretinin, and Syn. According to the results of the immunohistochemical analyses, plasma cell tumor was suspected.

A bone scan (in the beginning of April, 2013) showed an uneven distribution of elevated radioactivity at the skull and

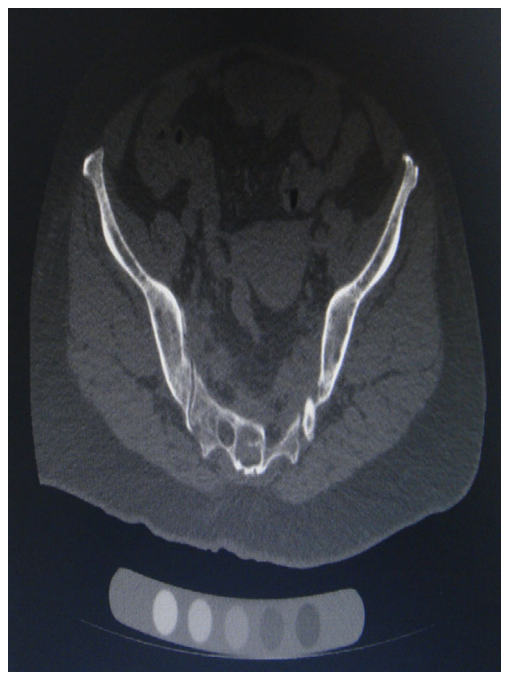

Figure 9. Pelvic CT (in the beginning of May, 2013) show destruction at multiple lumbar and pelvic bones.

increased punctate distribution of radioactivity at the left rib numbers 5 and 6 . The scan also showed uneven distribution of increased radioactivity at T11-L1 vertebrae, including sparse areas with radioactivity, and increased radioactivity at the right tuberositas femoris, left femur, and left tibia (Fig. 8). Lumbar and pelvic CT (in the beginning of May, 2013) showed there were destructions at multiple lumbar and pelvic bones, and there were small, patchy, low-density shadows at the bilateral femurs (Fig. 9, 10).

The flow cytometry results of the pleural effusion (in the beginning of May, 2013) showed that $84.69 \%$ of the nucleated cells expressed CD38, CD56, CD138, and C $\lambda$, however, they did not express CD27, CD28, CD117, CD20, CD 19 , C kappa, cIgM, HLA-DR, $\kappa$, or $\lambda$. The cells in the pleural effusion were malignant monoclonal plasma cells.

The results of a bone marrow biopsy showed hyperplasia of the nucleated cells. The granulocyte/erythroid ratio was 3.24. Granulocytes accounted for $60 \%$ and erythroid cells accounted for $18.5 \%$ of the total cell number. Each developmental stage of the hematopoietic cells was present. Granulocytes and monocytes were observed. Plasma cells accounted for $6.5 \%$ and all of them were immature.

A peripheral blood smear was normal. A bone marrow biopsy was performed at the posterior iliac spine, with an acceptable length of the specimen. In the marrow, there were a large number of monotonous cells with medium to large cell volume. Additionally, the cytoplasm was pink (H\&E staining) without significant particles, and there was a large, round, or irregularly-shaped small, red nucleolus. No wheelshaped karyon was observed. Immunohistochemical staining was positive for MUM1, CD138 reticulocytes, and negative for MPO, CD43, CD99, TdT, CD34, $\kappa, \lambda$, CD20, CD3, and CD117. The malignant cells were bulky and immature. The patient's diagnosis was non-secretory MM, DSS stage IIIA; ISS stage I.

The second patient with MPE was a 57-year-old man who was admitted in April 2011 for treatment. He had right 
shoulder pain and a $10-\mathrm{cm}$ painless lump at the back of the right shoulder for 2 months. An X-ray showed a right clavicle fracture. Shoulder CT showed destruction of the right clavicle and the right ninth rib. Chest CT showed osteolytic destruction at the right side of the distal clavicle and the right ninth rib, a soft tissue mass, and destruction at multiple ribs. A whole body isotope bone scan showed abnormalities of the right distal clavicle and the right posterior ribs (6 and 9) associated with a pathological fracture of the right clavicle. Blood leukocytes were $5.08 \times 10^{9} / \mathrm{L}$, hemoglobin was $138 \mathrm{~g} / \mathrm{L}$ and the platelet count was $159 \times 10^{9} / \mathrm{L}$. The serum alanine aminotransferase and aspartate transaminase levels were normal. The serum level of albumin was $41 \mathrm{~g} / \mathrm{L}$, creatinine was $84 \mu \mathrm{mol} / \mathrm{L}$, and calcium was $2.28 \mathrm{mmol} / \mathrm{L}$. The lipid, enzyme, lactate dehydrogenase, potassium, sodium, and chloride levels were normal. The erythrocyte sedimentation rate was $27 \mathrm{~mm} / \mathrm{h}$. The serum level of $\beta 2$ microglobulin was $4.2 \mathrm{mg} / \mathrm{L}, \operatorname{IgA}$ was $11.7 \mathrm{~g} / \mathrm{L}$, and $\kappa$ light chain was $10.7 \mathrm{~g} / \mathrm{L}$; moreover, $\operatorname{IgG}, \operatorname{IgM}$, and $\lambda$ light chains were reduced. Monoclonal $\operatorname{IgA} \kappa$ light chain was observed at the $\beta$-area using serum immunofixation electrophoresis. $\mathrm{K}$ light chain was observed using urinary immunofixation electrophoresis. K light chain in the 24-hour urine was 257.4 $\mathrm{mg}$. Plasma cells in the bone marrow smears accounted for $4.5 \%$ of the total cells. Flow cytometry of the bone marrow showed that $3.81 \%$ of the nucleated cells were abnormal clonal plasma cells. A biopsy of the tumor at the right shoulder showed plasma cell tumor [positive for CD38, CD138, Ki-67 (10\%), and MUM1, and negative for CD79a]. The diagnosis was MM IgA- $\kappa$, DSS stage IIIA; ISS stage II.

After chemotherapy, the disease showed partial remission, however, progression occurred 1.5 years later. Fatigue, wheezing, and other symptoms emerged. A medium amount of right pleural effusion appeared, and pericardial effusion and ascites were found by CT. The pleural effusion was yellow exudate, and lacked physical and chemical characteristics. Myeloma cells in the pleural effusion were found by the smear. The flow cytometry results showed that $41.98 \%$ of the nucleated cells in the pleural effusion expressed

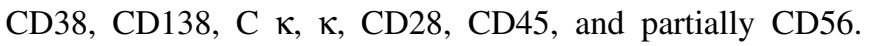
There was no expression of CD117, C $\lambda, \mathrm{CD} 27, \mathrm{CD} 19, \lambda$, or CD20. MPE was confirmed. Flow cytometry confirmed that the myeloma cells were also present in the pericardial effusion and ascites of the patient. Myeloma cells in the ascites were found by the smear, however, those in the pericardial effusion were not found by the smear.

\section{Discussion}

$\mathrm{MM}$ is usually invasive to the bone marrow, as well as to other sites. MPE is diagnosed according to the findings of myeloma cells in pleural effusion $(7,12,13)$. Among the causes of pleural effusion, myeloma cell infiltration or invasion to the pleura is rare. We studied 3,480 patients with pleural effusion and 319 patients with MM who were admitted to Beijing Jishuitan Hospital over an approximate 10- year period. Among them, 34 patients had both MM and pleural effusion, accounting for $11 \%$ of MM patients. There were only two cases with MPE, of which only one case with pleural effusion as the initial manifestation was treated in the respiratory department. The first MPE patient described in detail above had non-secretory MM, and monoclonal immunoglobulin was not found in her blood or urine. The diagnosis and treatment of this patient did not go well. After the physician obtained tissue from the patient's pleural lesions and pleural effusion cells, the pathological slices were sent to three main hospitals for pathology consultation. All of the pathologists considered that it was malignant disease, however, they were unsure about the source of the pathology and the type of disease. Ultimately, non-secretory MM was diagnosed using flow cytometry of the pleural effusion specimen. A bone marrow biopsy was subsequently performed which confirmed the diagnosis. The second case of MPE was diagnosed with MM at the initial stage. During treatment, the patient's health deteriorated and MPE emerged. The pleural effusions of the two patients were yellow exudates. The first MPE patient showed bilateral pleural effusion (a medium amount in the right and a small amount in the left). The second MPE patient had a medium amount of pleural effusion for the first time on the right side, and then developed bilateral pleural effusion. There were no specific traits of pleural effusion, except for elevated CA125 levels. Elevated CA125 is very common in patients with effusion. These two MPE patients accounted for $0.6 \%$ (2/319) of the cases of MM and only $0.06 \%$ of 3,480 cases of pleural effusion. Because the incidence of MPE is low, little is known about the disease.

To further investigate the incidence of pleural effusion in patients with MM, we conducted a literature review. Reports of MPE were mostly case reports. Few studies with a large sample have been reported. Usmani et al. summarized 1,965 cases of MM (14). Positron emission tomographic (PET) scans were performed to check for extramedullary involvement. They found that the presence of onset of MM patients with pleural involvement accounted for $3 \%$, while accounting for $6 \%$ of the disease progression. However, they did not describe the occurrence of pleural effusion.

Young-Uk Cho et al. summarized 734 cases of MM, and 54 cases had pleural effusion, accounting for 7\% (15). Among them, 42 cases had complete data. Malignant plasma cells were found in the pleural effusion by pathological examinations in 19 patients. These 19 patients were ultimately diagnosed with MPE. Twenty-three patients had benign pleural effusion. In the literature, MPE patients account for $2.6 \%$ of MM patients (15).

We collected data on 34 patients with both MM and pleural effusion, accounting for $11 \%$ of MM patients, and only two patients had MPE. The incidence of MPE in our study was lower than that in previous studies. Possible reasons for this low incidence of MPE are as follows: (1) flow cytometry was not carried out for each patient. Myeloma cells were detectable only in the flow cytometric analyses, not in the 
pericardial effusion smears. This indicates that a simple pathology smear has a high specificity and low sensitivity. According to the metabolism levels of the cells, a PET scan is used to distinguish between benign and malignant lesions. PET can confirm the involvement of the pleura, however, it cannot definitively determine the existence of MPE. (2) Different regions, races, and treatment methods were also associated with differences in the incidence of MPE, and different laboratory conditions and other factors could lead to differences in the results.

The causes of pleural effusion with $\mathrm{MM}$ are diverse, and include nephrotic syndrome, pulmonary embolism, pulmonary infection, hypoalbuminemia, heart failure caused by cardiac amyloidosis, and infiltration of tumor cells $(1,3,7)$. In our study, the causes of pleural effusion in the $34 \mathrm{MM}$ patients included the above-mentioned factors, as well as tuberculous pleurisy, cirrhosis, and pulmonary hypertension. MPE is considered as the end-stage of disease or the progression of disease.

In summary, for malignant pleural effusion, physicians should consider not only primary malignant tumor in the chest or metastasis of systemic solid tumors, but also hematonosis. Flow cytometry is widely used in the diagnosis, identification, disease monitoring, evaluation of efficacy, and prognosis in various fields, such as hematology, immunology, oncology, and genetics. However, flow cytometry is not widely used in the diagnosis of pleural effusion. We consider that flow cytometry is fast, accurate, and has objective characteristics in the identification and analysis of cells, and is therefore a useful complement to traditional diagnostic methods of pleural effusion.

\section{Conclusion}

The detection rate of MPE was very low. MPE patients produced yellow exudates, which lacked physical and chemical characteristics. There were many yellow nodules on the pleura of patient with MPE. These nodules were lobulated and had abundant blood supply. Routine pleural effusion pathological examinations had low sensitivity. Flow cytometry may therefore be useful for improving the detection rate of MPE.
The authors state that they have no Conflict of Interest (COI).

\section{References}

1. Kintzer JS, Rosenow EC, Kyle RA. Thoracic and pulmonary abnormalities in multiple myeloma. Arch Intern Med 138: 727-730, 1978.

2. Badrinas F, Rodriguez-Roisin R, Rives A, Picado C. Multiple myeloma with pleural involvement. Am Rev Respir Dis 110: 8287, 1974.

3. Hughes JC, Votaw ML. Pleural effusion in multiple myeloma. Cancer 44: 1150-1154, 1979.

4. Estrov Z, Berrebi A, Hazani E, et al. Pleural effusion and ascites as presenting signs of IgA myeloma. Haematologica 68: 105-109, 1983.

5. Shoenfeld Y, Pick AI, Weinberger A, et al. Pleural effusionpresenting sign in multiple myeloma. Respiration 36: 160-164, 1978.

6. Kapadia SB. Cytological diagnosis of malignant pleural effusion in myeloma. Arch Pathol Lab Med 101: 533-534, 1977.

7. Rodriguez JN, Pereira A, Martinez JC, Conde J, Pujol E. Pleural effusion in multiple myeloma. Chest 105: 622-634, 1994.

8. Angrish K, Dawar R, Verma K. Malignant pleural effusion in myeloma: cytologic diagnosis. Indian J Pathol Microbiol 23: 267271, 1980.

9. Kyle RA. Multiple myeloma: review of 869 cases. Mayo Clin Proc 50: 29-40, 1975.

10. Meoli A, Willsie S, Fiorella R. Myelomatous pleural effusion. Southern Med J 90: 65-68, 1977.

11. Alexandrakis MG, Passam FH, Kyriakou DS, Bouros D. Pleural effusions in hematologic malignancies. Chest 125: 1546-1555, 2004.

12. Palmer HE, Wilson CS, Bardales RH. Cytology and flow cytometry of effusions of multiple myeloma. Diagn Cytopathol 22: 147151, 2000.

13. Deshpande AH, Munshi MM. Pleural effusion as an initial manifestation of multiple myeloma. Acta Cytol 44: 103-104, 2000.

14. Usmani SZ, Heuck C, Mitchell A, et al. Extramedullary disease portends poor prognosis in multiple myeloma and is overrepresented in high-risk disease even in the era of novel agents. Haematologica 97: 1761-1767, 2012.

15. Cho YU, Chi HS, Park CJ, Jang S, Seo EJ, Suh C. Myelomatous pleural effusion: a case series in a single institution and literature review. Korean J Lab Med 31: 225-230, 2011.

(C) 2016 The Japanese Society of Internal Medicine http://www.naika.or.jp/imonline/index.html 